\title{
Early diagnosis of keratoconus: what difference is it making?
}

\author{
Joaquín Fernández Pérez, Almudena Valero Marcos, \\ Francisco Javier Martínez Peña
}

\section{WHY EARLY DIAGNOSIS?}

In corneal refractive surgery, early diagnosis of keratoconus (subclinical asymptomatic keratoconus) is of great importance in patients seeking surgery because it can prevent progression of the pathology after surgery and make it symptomatic (corneal ectasia), thus creating the need for diagnostic tests that provide high sensitivity (ability to detect the disease in affected subjects) with the objective that no asymptomatic subclinical keratoconus ends up not being diagnosed and thus not undergo corneal refractive surgery. Recently, Uçakhan et $a l^{1}$ investigated several Pentacam parameters in subclinical keratoconus, keratoconus and normal eyes. They found that the Scheimpflug system could differentiate between ectatic and normal eyes. In this study, the optimum cut-off point for posterior elevation was found to be $26.5 \mu \mathrm{m}$ (97.7\% sensitivity and $81.0 \%$ specificity). In a study by Mihaltz et $a l^{2}$, receiver operating characteristic (ROC) curve analysis indicated that posterior elevation was the most important criterion in the diagnosis of keratoconus. A threshold value of $15.5 \mu \mathrm{m}$ had sensitivity of $95.1 \%$ and specificity of 94.3\% for differentiating normal eyes from keratoconus. These authors found lower pachymetry readings in subclinical, early and moderate keratoconus; however, they did not find significant differences in these parameters between subclinical keratoconus and normal eyes.

In the general population, the prevalence of keratoconus is $1 / 2000 .^{3} 4$ If the prevalence of a particular disease in a population is low, the positive predictive value tends to be low given that having a greater number of healthy people increases the number of false positives.

As the prevalence of keratoconus in the general population is low, to reach a conclusive diagnosis in early stages we would have to reconfirm the result with a second independent test since a single positive result would not be conclusive.

Department of Ophthalmology, Qvision, Vithas Vírgen del Mar Hospital, Almería, Spain

Correspondence to Dr Joaquín Fernández Pérez, Department of Ophthalmology, Qvision, Vithas Vírgen del Mar Hospital, Ctra Mamí km 1, Almería CP. 04120, Spain; joaquinfernandezoft@gmail.com
However, with the goal of designing screening protocols that improve the ratio of cost-effectiveness we are led to search for diagnostic criteria that maximise the prevalence of the disease in certain population groups in order to increase the positive predictive value of these diagnostic tests.

The prevalence in patients with astigmatism greater than $2 \mathrm{Dp}$ increased to $14.1 \%$ (6.3\% of eyes had keratoconus and $7.8 \%$ had subclinical keratoconus).

\section{WHAT DIAGNOSTIC TOOLS DO WE CURRENTLY RELY ON?}

The computerised videokeratography for keratoconus diagnosis was first introduced in the 1980s. These systems used analysis of Placido disk images to compute anterior corneal curvature. A zone of increased corneal power surrounded by zones of decreasing corneal power, inferiorsuperior asymmetry in corneal power and skewing of the steepest radial axes above and below the horizontal meridian was established as characteristic of keratoconus on videokeratography maps. Several indices have been developed to discriminate keratoconus and subclinical keratoconus from normal eyes, as well as progression, thus improving the sensitivity of these tests. Some of the most popular include the keratoconus prediction index of the Klyce-Maeda group and the Rabinowithz KISA index per cent. ${ }^{5} 6$

The development and increase of refractive surgery techniques caused an increase in ectatic disease, and so in the 1990s more sophisticated systems were developed; known as eye imaging instruments, these tools are used to detect suspicious corneas and to make an early diagnosis.

Orbscan I (Bausch \& Lomb, Rochester, New York, USA) is an eye imaging instrument which uses slit scanning technology to provide wide-field pachymetry and anterior and posterior elevation maps as well as keratometry. Later, Orbscan II combined slit scanning with Placido-based topography analysis making it more sensitive to early diagnosis. Measurements to be taken into consideration with this instrument in order to detect keratoconus in normal subjects are: maximum rear elevation compared with the best fit sphere (BFS), irregularity in the central 3 and $5 \mathrm{~mm}$ zones as well as pachymetry. To assess progression in patients with keratoconus, we consider increase in apex elevation, displacement of the corneal apex, decrease in thinnest-point pachymetry and an increase in the mean simulated keratometry minimum.

Another surveyor, Pentacam (Oculus, Wetzlar, Germany), is based on the Scheimpflug principle, which provides a 3D mapping of the cornea from 25000 actual lifting points, including measurement of anterior and posterior surfaces of the cornea, corneal thickness and angle anterior chamber. A prominent feature of Pentacam is the improved map for ectasia detection analysis by Belin/Ambrosio; in order to calculate an elevation, a reference sphere (BFS) is used with a radius depending on the K. Next, the sphere (BFS) is optimised, excluding the central area of $4 \mathrm{~mm}$, thus highlighting pathologies and facilitating the detection of subclinical keratoconus. This surveyor gives us an idea of the aberrations in eyes with keratoconus; there will be a significant increase in vertical coma, primary coma and coma aberrations. ${ }^{7}$ Another index that facilitates early diagnosis of keratoconus versus normal eyes is the pachymetric progression index. ${ }^{8}$

These surveyors complement each other in daily clinical practice enabling an increase in the detection of subclinical keratoconus. Differences were detected in the values of both instruments with slightly smaller values in Pentacam versus Orbscam I. ${ }^{9}$ However, no differences were detected in the minimum pachymetric value but instead in the subsequent lifting of the best sphere fit in spite of similar curvature radii in Pentacam versus Orbscam II. This difference can be useful in order to avoid refractive surgery in patients with subclinical keratoconus. ${ }^{10}$

Thanks to all these indices, surveyors are currently the most sensitive test available to us and the most highly specific. But the search for new methods that allow us to make a diagnosis as early as possible goes even further. With the methods currently developed, we have greatly increased the capacity to detect corneas that are suspicious of keratoconus, although with it brings an increase in false positives in our clinical daily practice.

Wavefront aberrometers (WavefrontAbbott, WaveLight Analyzer-Alcon, Maxwell-Ziemer or Zywave-Technolas PV) allow for evaluation of the Zernike coefficients of the anterior surface and posterior corneal and higher order 
aberrations, being increased in patients with keratoconus or subclinical keratoconus. ${ }^{11-13}$

Until recently, evaluation of corneal biomechanics was feasible only in vitro. Today we can measure using the Ocular Response Analyzer (Reichert Inc., Depew, New York, USA) to detect lower levels of corneal hysteresis and corneal resistance factor, both in keratoconus patients and healthy relatives of patients with keratoconus. ${ }^{14} 15$ Alternative parameters and their combination provide greater accuracy. ${ }^{16} 17$

The spectral-domain optical coherence tomography (OCT) (Spectralis, Heidelberg Engineering) provides details about the distribution of corneal epithelial and stromal thicknesses. The epithelium and stroma in keratoconic eyes were thinner inferotemporally and thicker supranasally compared with healthy eyes. The distribution pattern was more distinct in epithelium than in stroma. ${ }^{18}$ The OCT for ultrahigh resolution (Artemis, Arc Scan) detects a smaller thickness of the epithelium and Bowman layer, showing an epithelial pattern like a donut, with a more thickened periphery and thinned in the centre of eyes with keratoconus enabling for an earlier diagnosis. ${ }^{19-21}$ The polarisation-sensitive OCT (PS-OCT 1300 , Thorlabs) can detect an increase in the average face phase retardation of the posterior surface of the cornea in keratoconus patients due to changes in the lamellar structure of collagen fibres, which may be useful in early diagnosis. ${ }^{22}$

Confocal microscopy provides a study of the microstructure of the cornea. In patients with keratoconus or subclinical keratoconus, the anterior and posterior stromal keratocyte densities are lower and stromal nerve diameter is higher, although these changes are not specific to the disease. This should be considered as an additional technique. ${ }^{23} 24$

The potential of Fourier Transform Infrared (FTIR) spectroscopy is combined with advanced chemometric processing of spectral data for the analysis of raw tears. This technique can be performed in patients with various eye diseases including keratoconus. Patients with keratoconus and patients with non-specific inflammatory eye diseases show variations in spectral ranges mainly attributed to lipids and carbohydrates. This analysis can be used as a complement to early diagnosis. $^{25}$

The Optical Quality Analysis System, a double pass system (Visiometrics SL, Terrassa, Spain), has been used for the detection of keratoconus and subclinical keratoconus. The Strehl ratio and modulation transfer function measurements are seen as altered in these patients. ${ }^{26}$

\section{WHAT ARE THE CHALLENGES AHEAD?}

The challenges we face in the future are treatments that increase the effectiveness in halting disease progression in asymptomatic subclinical stages and preserving visual quality and highly specific diagnostic equipment to avoid applying unnecessary treatments in false positives.

Contributors All authors were involve in drafting and revising the article, and approval of the final version.

Competing interests None.

Provenance and peer review Commissioned; internally peer reviewed.

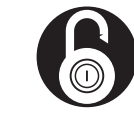

\section{OPEN ACCESS}

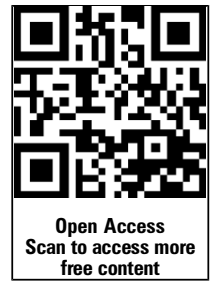

Open Access This is an Open Access article distributed in accordance with the Creative Commons Attribution Non Commercial (CC BY-NC 3.0) license, which permits others to distribute, remix, adapt, build upon this work non-commercially, and license their derivative works on different terms, provided the original work is properly cited and the use is noncommercial. See: http://creativecommons.org/licenses/ by-nc/3.0/

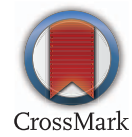

To cite Fernández Pérez J, Valero Marcos A, Martínez Peña FJ. Br J Ophthalmol 2014;98:1465-1466.

Published Online First 23 April 2014

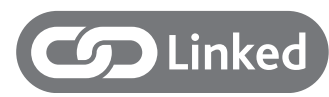

- http://dx.doi.org/10.1136/bjophthalmol-2013304494

Br J Ophthalmol 2014;98:1465-1466. doi:10.1136/bjophthalmol-2014-305120

\section{REFERENCES}

1 Uçakhan ÖÖ, Cetinkor V, Özkan M, et al. Evaluation of Scheimpflug imaging parameters in subclinical keratoconus, keratoconus, and normal eyes. J Cataract Refract Surg 2011;37:1116-24.

2 Miháltz K, Kovács I, Takács A, et al. Evaluation of keratometric, pachymetric, and elevation parameters of keratoconus corneas with pentacam. Cornea 2009:28:976-80.

3 Rabinowitz YS. Keratoconus. Surv Ophthalmol 1998:42:297-319.

4 Kennedy RH, Bourne WM, Dyer JA. A 48-year clinical and epidemiologic study of keratoconus. Am J Ophthalmol 1986:101:267-73.

5 Vazirani J, Basu S. Keratoconus Current perspectives. Clin Ophthalmol 2013;7:2019-30.

6 Sedghipour MR, Sadigh AL, Motlagh BF. Revisiting corneal topography for the diagnosis of keratoconus: use of Rabinowitz's KISA\% index. Clin Ophthalmol 2012;6:181-4

7 Piñero DP, Alió JL, Alesón A, et al. Pentacam posterior and anterior corneal aberrations in normal and keratoconic eyes. Clin Exp Optom 2009;92: 297-303.

8 Ambrósio R Jr, Caiado AL, Guerra FP, et al. Novel pachymetric parameters based on corneal tomography for diagnosing keratoconus. J Refract Surg 2011;27:753-8.

9 DU XL, Chen M, Ma L, et al. Comparison of Pentacam and Orbscanll systems for the diagnosis of keratoconus suspects. Zhonghua Yan Ke Za Zhi 2012:48:323-9.

10 Quisling S, Sjoberg S, Zimmerman B, et al. Comparison of Pentacam and Orbscan Ilz on posterior curvature topography measurements in keratoconus eyes. Ophthalmology 2006;113:1629-32.

11 Bühren J, Kook D, Yoon G, et al. Detection of subclinical keratoconus by using corneal anterior and posterior surface aberrations and thickness spatial profiles. Invest Ophthalmol Vis Sci 2010;51:3424-32.

12 Bühren J, Kühne C, Kohnen T. Defining subclinical keratoconus using corneal first-surface higher-order aberrations. Am J Ophthalmol 2007;143:381-9.

13 Bühren J, Kühne C, Kohnen T. Wavefront analysis for the diagnosis of subclinical keratoconus. Ophthalmologe 2006;103:783-90.

14 Gatzioufas Z, Seitz B. New aspects on biomechanics of the cornea in keratoconus. Ophthalmologe 2013; 110:810, 812-17

15 Kara N, Altinkaynak H, Baz O, et al. Biomechanical evaluation of cornea in topographically normal relatives of patients with keratoconus. Cornea 2013;32:262-6.

16 Touboul D, Bénard A, Mahmoud AM, et al. Early biomechanical keratoconus pattern measured with an ocular response analyzer: curve analysis. J Cataract Refract Surg 2011:37:2144-50.

17 Ventura BV, Machado AP, Ambrósio R Jr, et al. Analysis of waveform-derived ORA parameters in early forms of keratoconus and normal corneas. J Refract Surg 2013;29:637-43.

18 Zhou W, Stojanovic A. Comparison of corneal epithelial and stromal thickness distributions between eyes with keratoconus and healthy eyes with corneal astigmatism $\geq 2.0$ D. PLOS ONE 2014;9:085994.

19 Yadav R, Kott aiyan R, Ahmad K, et al. Epithelium and Bowman's layer thickness and light scatter in keratoconic cornea evaluated using ultrahigh resolution optical coherence tomography. J Biomed Opt 2012:17:116010.

20 Reinstein DZ, Archer TJ, Gobbe M, et al. Repeatability of layered corneal pachymetry with the artemis very high-frequency digital ultrasound arc-scanner. J Refract Surg 2010;26:646-59.

21 Reinstein DZ, Archer TJ, Gobbe M. Corneal epithelial thickness profile in the diagnosis of keratoconus. J Refract Surg 2009;25:604-10.

22 Fukuda S, Yamanari M, Lim Y, et al. Keratoconus diagnosis using anterior segment polarization-sensitive optical coherence tomography. Invest Ophthalmol Vis Sci 2013:54:1384-91.

23 Ozgurhan EB, Kara N, Yildirim A, et al. Evaluation of corneal microstructure in keratoconus: a confoca microscopy study. Am J Ophthalmol 2013:156:885-93.

24 Egorova GB, Rogova Ala, Mitichkina TS. Diagnostic value of confocal microscopy in primary corneal ectasia. Vestn Oftalmol 2012;128:25-9.

25 Travo A, Paya C, Déléris G, et al. Potential of FTIR spectroscopy for analysis of tears for diagnosis purposes. Anal Bioanal Chem 2014;406: 2367-76

26 Ye C, Ng PK, Jhanji V. Optical quality assessment in normal and forme fruste keratoconus eyes with a double-pass system - a comparison and a variability study. Br J Ophthalmol 2014;98:1478-83. 